\title{
The Efficiency of Hirudotherapy in Venous Congestion Treatment Atfer Replantation
}

\author{
MIHAELA PERTEA ${ }^{1,2}$, OXANA-MADALINA GROSU ${ }^{1,2 *}$, DANIEL TIMOFTE ${ }^{1}$, \\ NATALIA VELENCIUC ${ }^{1,3}$, PETRU CIOBANU ${ }^{1}$, VLADIMIR POROCH ${ }^{1,4 *}$, \\ SORINEL LUNCA ${ }^{1,3}$ \\ ${ }^{1}$ Grigore T. Popa University of Medicine and Pharmacy, Faculty of Medicine, 16 Universitatii Str., 700115, Iasi, Romania \\ ${ }^{2}$ Clinic of Plastic and Reconstructive Microsurgery, „Sf. Spiridon” Emergency Hospital, 1 P-ta Independentei, 700111, Iasi, \\ Romania \\ ${ }^{3}$ Second Clinic of Surgical Oncology, Regional Institute of Oncology, 2-4 G-ral Berthelot Str., 700483, Iasi, Romania \\ ${ }^{4}$ Palliative Care Department, Regional Institute of Oncology, 2-4 G-ral Berthelot Str., 700483, Iasi, Romania
}

Abstract. Hirudotherapy is a complementary medical technique, apparently old, but, at the same time, an up to date technique, having a real efficiency in the treatment of venous congestion. Hirudin, present in the leeches' saliva, was isolated by Markwardt in 1955. It acts by preventing the conversion of fibrinogen into fibrin, thus being a natural inhibitor of thrombin. The saliva of the leeches also contains over 100 proteins with various molecular weights, having an important anticoagulant, antiinflammatory and analgesic effects, platelet function inhibitor, thrombin function regulator and antimicrobial. The purpose of the study is to confirm the effectiveness of the use of hirudotherapy in the treatment of venous congestion occurring post-replantation, as well as to emphasize some peculiarities of usage, duration and results in the case of using leeches in the treatment of venous congestion.The study included a group of 29 cases, 7 with ear amputations (three cases of complete amputation and four cases of incomplete amputation) and 22 cases of complete finger amputations. For the ears, in complete amputation, microsurgical replantation and arterial reconstruction were performed without being able to identify a vein for microsurgical anastomosis. Postoperatively, in all cases, once the signs of venous congestion had occurred, Medical Leech Therapy (MLT) was initiated. The application of medicinal leaches was initiated several hours postoperatively in those cases of distal digital amputation when no vascular anastomosis was performed, as well as in those where conventional treatment (local heat, elevated hand, general vasodilators and local heparin) was not effective.

Keywords: ear, finger, leech, replantation, hirudotherapy

\section{Introduction}

Leeches are segmented, hermaphroditic, carnivorous worms, very sensitive to touch, vibration, heat, sound and different chemicals. One can count in their saliva over 20 active substances [1] with analgesic, anticoagulant, platelet inhibitory, thrombin regulatory and antimicrobial effects combined with the low costs, efficiency and easy use, makingthe medicinal leech therapy (MLT) to be used in the treatment of venous congestion both in replantation and revascularization, as well as in microsurgical free tissue transfers.

The use of leeches for medical purposes is mentioned since ancient Egypt [2, 3], Galen used leeches in the treatment of hemorrhoids, different types of inflammation and, even, in mental illnesses [4] and Avicenna (980-1037 AD) applied them in skin diseases [5]. The interest for the medical use of leeches persisted throughout the Middle Ages, but during the second half of the $19^{\text {th }}$ century it began to fall into disgrace[6].The name "leech" was assigned by Linnaeus in 1758, being derived from the word "laece", meaning "physician" [6] and in 1884 Haycraft discovered the hirudin, its antithrombotic effect

\footnotetext{
*email: grosu.oxana@gmail.com; vladimir.poroch@umfiasi.ro
} 
being demonstrated in 1955 by Markwardt who isolated hirudin from leeches' pharyngeal glands [7, 8]. Since 1960, leeches have been proposed in the treatment of venous congestion, so that, the very same year, Deganc and Zdravicused them in the treatment of congested flaps [9]. In 1981, the Foundation for the Growth and Multiplication of Leechesinitiated by the biologist Roy T. Sawyer was established [6].

In "contemporary" plastic surgery, in 1980, Guy Foucher used leeches to relieve venous congestion in finger replantations [10] and in 2005, Frodelused them following the amputations of the nasal lobe, ear, lip and scalp [11]. Soon after leeches began to be used in medicine, the first studies on leeching complications appeared; thus, in 1983, Aeromonas hydrophila and Aeromonas veronii infections are mentioned after leech therapy and Whitlock et al. showed the increased risk of infection with these bacteria in thepoorlyvacuolated tissues [12, 13]. In 2004, medicinal leeches were approved by the U.S. FDA as a medical device.

The paper aims to present the results obtained on a group of 29 patients (seven cases with complete or partial ear amputations and 22 cases with distal thumb and long finger amputations) in which MLT was success fully used in the treatment of venous congestion during the immediate postoperative period. The moment when leeches were applied, daily frequency of their use, treatment duration, number of leeches used in each case, recorded complications, the use of concomitant treatments and the immediate and late results were studied.

\section{Materials and methods}

The study included a group of 29 cases, of which 7 with ear amputations (three cases of complete amputation and four cases of incomplete amputation) and 22 cases of complete finger amputations. All patients were admitted to the Plastic Surgery Clinic in Iasi, Romania. Informed consent was obtained from all patients at the time of admission. Also, while establishing the indication for the use of MLT, all patients were informed and counseled psychologically regarding this treatment. In the cases of complete ear amputations (three cases), microsurgical replantation and arterial reconstruction were performed without being able to identify a vein for microsurgical anastomosis (Figures. 1 and 2). In incomplete amputations (two cases in which less than $1 / 3$ and two cases in which over $1 / 3$ of the auricle was amputated, all located in the upper part of the auricle) no microsurgical anastomosis was performed (Figure 3).
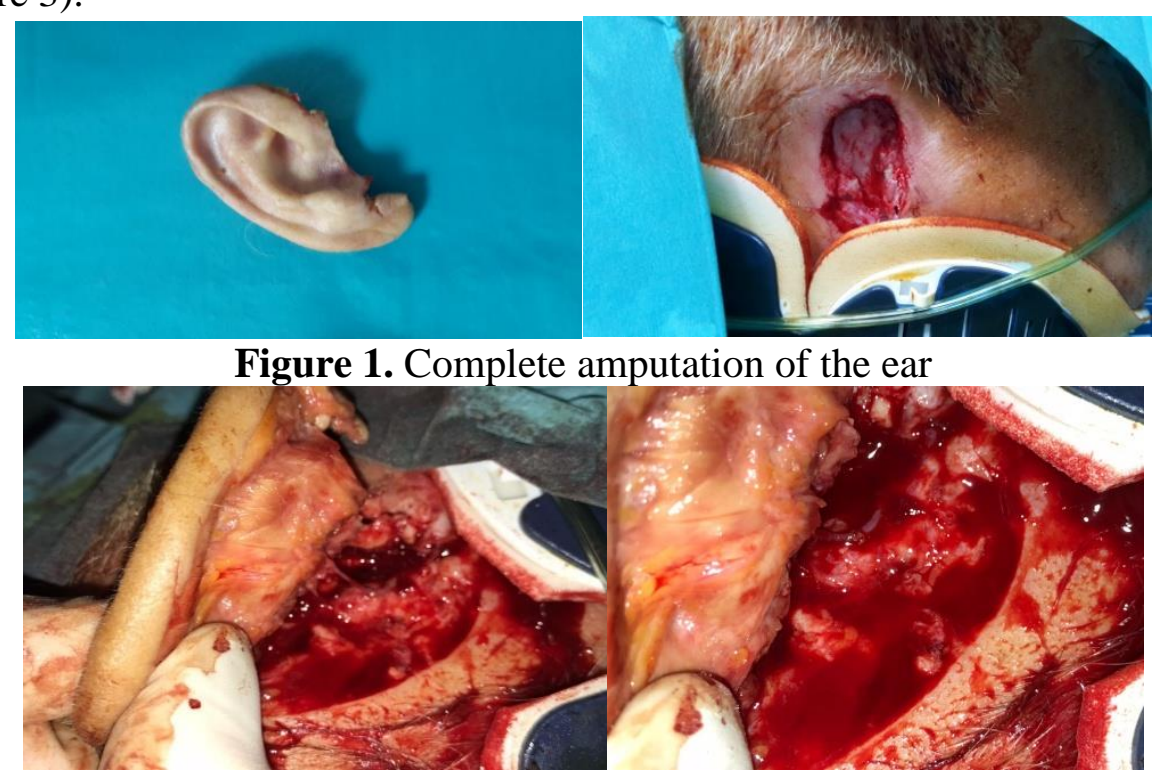

Figure 2. Replantation of the ear only arterioraphy

Postoperatively, in all cases, oncethe signs of venous congestion had occurred, MLT was initiated. From the digital amputation cases, we included in the study only those cases in which the trauma 
mechanism was avulsion, thus where microsurgical anastomoses were not possible or the rate of vascular thrombosis, especially of the venous one, was high (Figure 3).

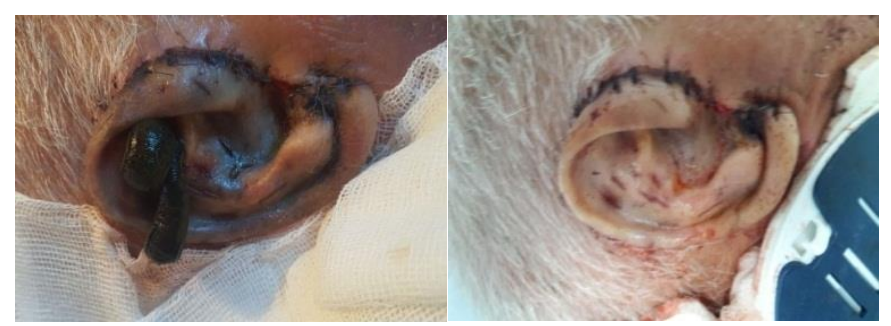

Figure 3. Medical Leech Therapy (MLT)

Out of the 22 study cases, in 6 cases the amputation was at first phalanx (F1) level, in three cases arterial and venous anastomoses and in the remaining 3 cases only arterial anastomosis being performed. On postoperative day, two cases with venous congestion occurred from the ones without venous anastomosis. In the other three cases, venous thrombosis occurred on postoperative day 3 . In 12 cases, the level of amputation was at second phalanx (F2). In 10 cases arterial anastomosis could be performed but the vein could not be microsurgically anastomosed, and in other two cases neither arterial nor venous microanastomoses were possible. Skin suture was performed with separate points locatedin the minimum possible number to diminish additional traumatothe skinand vascular capital. In the four cases who underwent distal amputation (distal phalanx - F3) none of the necessary arterial or venous microanastomoses was performed, but only the reattachment of the amputated segment at bone and skin level. In the immediate postoperative period, in all cases, a heparin solution was locally administered through a small finger pulp incision (biochemical leech) (Figures 4 and 5).

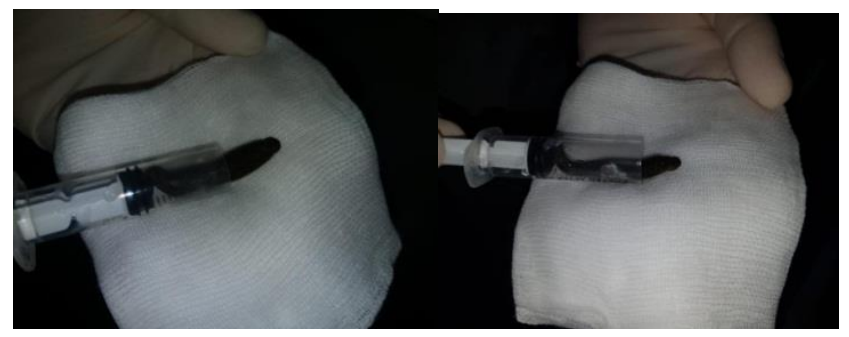

Fig. 4. Leech manipulation

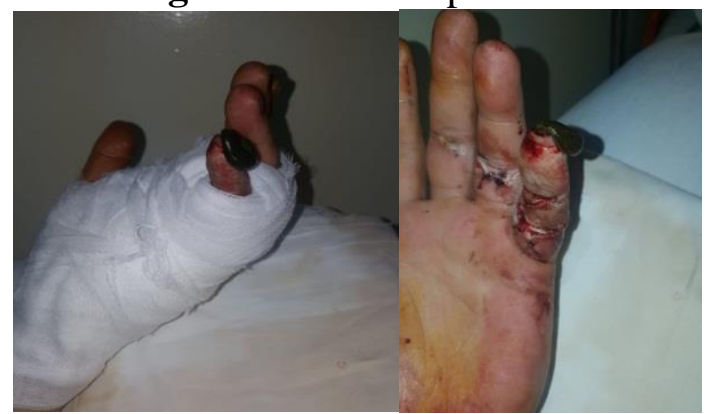

Fig. 5. Medical leech therapy in finger replantation

This treatment was applied according to a protocol in which the heparin administration is made according to a period of time corresponding to postoperative day number. Initially, in the immediate postoperative period all patients received continuous local warming, treatment generated with vasodilators. The application of medicinal leaches was initiated several hours postoperatively in cases of distal digital amputation when no vascular anastomosis was performed, as well as in cases where conventional treatment (local heat, elevated hand, general vasodilators and local heparin) was not 
effective. MLT was also initiated after postoperative day one in cases of F2 lesions when venous anastomosis was not performed. In the remaining cases, medicinal leeches were placed after the first signs of venous congestion were present. Leeches were applied at the level of the "skin window" in the finger pulp, initially made for the local administration of heparin.

Before application leeches should be kept in a container with clean water, not exposed to high temperatures. Doctors should wear gloves when handling leeches. Before application, leeches should be thoroughly rinsed and the area to be exposed to leeches should be cleaned with saline solution; leeches can be placed by hand or using a syringe whose nozzle had been removed with a scissors in order to place it better and easier on the area to be treated; bleeding in the recipient area should be stimulated; during leech therapy patients should be under permanent supervision, and attention should also be paid to leeches until their spontaneous detachment; the used leeches should be placed in a container other than the initial one. None of the patients receiving MLT had previously been diagnosed with blood disease, infections, hepatobiliary disease and malignancies or were known to be on chronic anticoagulant or immunosuppressive treatments. In all cases, in-between MLT sessions heparin was administered locally.

Antibiotic treatment was administered in all cases for the prophylaxis of infections due to the most often intense contamination of lesions but also for the prophylaxis of possible Aeromonas hydrophila infections due to the use of medicinal leeches. In all cases, ciprofloxacin $500 \mathrm{mg} / \mathrm{day}$ was used. The duration of MLT was variable, depending on the disappearance of the signs of venous congestion at the level of the amputated segment or occurrence of necrosis in the cases of therapeutic failure. During MLT, patient's complete blood count $(\mathrm{Hb}, \mathrm{Ht})$ was repeated and secretions were collected from both the suture path and from where the leeches were placed.

\section{Results and discussions}

Of the 22 patients with finger amputations, 19 were men and 3 women. The amputations involved the thumb in five cases and the long fingers in the remaining 17 cases. The number of used leeches was two to four per day, and the length of treatment ranged between 4 and 7 days. Blood transfusion was not indicated in any case although hemoglobin levels fell below $9 \mathrm{mg} / \mathrm{dL}$ in four of the cases of F1level digital amputations. No intolerance to leeches or psychological or emotional reactions during their application were recorded. MLT was used until the disappearance of venous congestion. The amputated segment survived in all cases in which venous anastomosis was performed but with the occurrence of venous congestion due to venous thrombosis. In two of the cases in which venous microanastomosis was not possible, an area of distal necrosis was identified, which subsequently benefited from necrectomy and epithelialization, and in two of the cases in which no microanastomosis was performed, the failure was total, with necrosis of the entire amputated segment (F3) followed by amputation stump retouch surgery. As a result, the success and effectiveness rate of MLT was 90.09\%. The secretions collected from the leech placement sites were negative in all cases, no case of MLTrelatedAeromonashydrophila infection being recorded (Table 1). Antibiotic treatment with ciprofloxacin was administered throughout the entire duration of MLT, being prolonged up to 12 days after its initiation.

Table 1. Results obtained following mlt use in digital replantations

\begin{tabular}{|c|c|c|c|c|c|c|}
\hline $\begin{array}{c}\text { Number } \\
\text { of study } \\
\text { cases }\end{array}$ & $\begin{array}{c}\text { Mean } \\
\text { treatment } \\
\text { duration }\end{array}$ & $\begin{array}{c}\text { Number of used } \\
\text { leeches } \\
\text { (average/day) }\end{array}$ & $\begin{array}{c}\text { Association } \\
\text { with other } \\
\text { treatments }\end{array}$ & $\begin{array}{c}\text { Complications/infections, intole- } \\
\text { rance,anemia, } \\
\text { (no.cases) }\end{array}$ & $\begin{array}{c}\text { Partial necrosis } \\
\text { (no. cases) }\end{array}$ & $\begin{array}{c}\text { Complete } \\
\text { necrosis } \\
\text { (no. cases) }\end{array}$ \\
\hline 22 & $4-7$ days & $2-4 /$ day & $\begin{array}{c}\text { Vasodilators } \\
\text { Local heparin }\end{array}$ & 0 & 2 & 2 \\
\hline
\end{tabular}

As to MLT used in complete or partial amputations the results were good. In the threereplantations with microsurgical arterial anastomoses, MLT successfully treated venous congestion, only in one case a small area of necrosis ( $3 \mathrm{~mm}$ wide and $1.5 \mathrm{~cm}$ long) being seen on the contour of the helix in which 
secondarilynecrectomyassociated with direct suture were performed without affecting the definitive aesthetic appearance of the ear. In cases of partial ear amputation, the results were good, with complete survival of the replanted segment. Late aesthetic results were also good, the patients being fully satisfied (Table 2).

Table 2. Diagram of patients who underwent ear replantation in which MLT was used

\begin{tabular}{|l|l|l|l|l|l|l|l|l|l|l|l|l|l|}
\hline & Sex & Age & $\begin{array}{l}\text { Complete } \\
\text { amputation }\end{array}$ & $\begin{array}{l}\text { Partial } \\
\text { Amputation }\end{array}$ & $\begin{array}{l}\text { Trauma } \\
\text { mechanism }\end{array}$ & $\begin{array}{l}\text { Arterial } \\
\text { micro- } \\
\text { anastomosis }\end{array}$ & $\begin{array}{l}\text { MLT } \\
\text { initiation } \\
\text { postop } \\
\text { day) }\end{array}$ & $\begin{array}{l}\text { No. } \\
\text { Used } \\
\text { leeches/ } \\
\text { day }\end{array}$ & $\begin{array}{l}\text { MLT } \\
\text { duration }\end{array}$ & $\begin{array}{l}\text { Antibiotic } \\
\text { pro- } \\
\text { phylaxis }\end{array}$ & $\begin{array}{l}\text { MLT- } \\
\text { generated } \\
\text { infection }\end{array}$ & $\begin{array}{l}\text { Complete/ } \\
\text { partial } \\
\text { viability }\end{array}$ \\
\hline 1 & $\mathrm{M}$ & 42 & + & - & avulsion & + & 2 & 3 & 5 & + & - & ++ \\
\hline 2 & $\mathrm{M}$ & 56 & + & - & avulsion/cut & + & 2 & 3 & 5 & + & - & ++ \\
\hline 3 & $\mathrm{M}$ & 58 & + & - & avulsion & + & 1 & 2 & 4 & + & - & ++ \\
\hline 4 & $\mathrm{M}$ & 65 & - & + & horse bite & - & 2 & 2 & 4 & + & - & - \\
\hline 5 & $\mathrm{M}$ & 49 & - & + & + & dog bite & - & 3 & 2 & 2 & 4 & + & - \\
\hline 6 & $\mathrm{M}$ & 72 & - & + & avulsion & - & 2 & 2 & 3 & + & - & ++ \\
\hline 7 & $\mathrm{M}$ & 35 & - & + & contusion & - & 1 & 3 & 4 & + & - & +++ \\
\hline
\end{tabular}

While there is a consensus that with the development of microsurgical techniques the end results of ear replantations have improved, venous congestion is a common complication, commonly encountered regardless of the technique used. Although venous anastomosis should be performed whenever possible, sometimes patient's venous capital is limited, making venorrhaphy impossible, or the trauma mechanism makes that vascular damage to be extensive or, sometimes, the significantlyprolongedoperative time to reconstruct venous return with prolonged anesthesia duration will not guarantee better outcomes, both locally and in terms of patient's general condition [14].

Venous congestion is estimated to occur in $61 \%$ of ear replantations in which arterial and venous anastomoses were restored and in 79\% of those in which only arterial anastomosis was restored; therefore, the microsurgical technique does not eliminate the risk of venous congestion, reason why MLT is often the only option for saving replanted tissues [15]. MLT reduces venous congestion not only by actively draining the blood in the replanted tissue, but also by the continued passive bleeding from leech wound after leech detachment due to the presence in the saliva of Hirudo medicinalis of over 100 biologically active substances, some with long-lasting action, which cause the persistence of bleeding [2]. Persistent bleeding from the Y-shaped wound caused by leech bite is a consequence of the bioactive enzymes, anticoagulants and vasodilators secreted by the leech [16]. An over 6-hour blood oozing was also noticed in our cases, and, as an adjuvant effect after leech detachment, we wiped the bite site withheparin-saline solutionand mechanically detached the formed clots to maintain bleeding for as long as possible, process known as "biochemical leeching". The oldest and most wellknown bioactive product in leech saliva is hirudin, a low molecular weight molecule, which is a specific non-enzymatic thrombin inhibitor [17].

An in vitro study also demonstrated the inhibitory effect of hirudin on factor IX [18]. But hirudin alone could not preserve blood oozing from leech bite wound. Substances with synergistic effect in leech saliva are proteinase inhibitors, such as bdellin (trypsin, plasmin and acrosin inhibitors), hirustasin (tissue kallikrein, trypsin, alpha-chymotrypsin, and granulocyte cathepsin G inhibitor), tryptase inhibitor, eglins ( $\alpha$-chymotrypsin, subtilisin, chymasin, and cathepsin $\mathrm{G}$ inhibitors), factor Xa inhibitor, carboxypeptidase inhibitors, and complement component C1 inhibitor [19]. Seratin is a recently discovered protein in the composition of leech saliva, and has been studied in terms of its effect on direct and indirect collagen-platelet interactions. This study shows that seratin inhibits von Willebrand factor-collagen binding and therefore inhibits collagen-mediated adhesions and platelet aggregation and activation, and subsequently thrombus formation in blood vessels [20]. Increased blood flow in tissues subjected to MLT is dueto histamine-like factors that cause microcirculatory vasodilation [16]. 
Acetylcholine, found in leech secretions, relaxes the endothelial muscles, thus favoring vasodilation [2]. It seems like the mechanism of action of the leech saliva is not yet well elucidated, because there are two publications from 2019 which describe two new biologically active substances isolated from leech saliva. One of them is bdellin-HM-2, a protein with 132 amino acids with anticoagulant properties [21].

Another one is hirudin-HN, an 89 amino acids protein containing the typical structure characteristics of hirudin [22]. Aeromonas hydrophila was isolated from the intestinal tract of medicinal leeches and it is believed they live in symbiosis. A. hydrophila denatures hemoglobin, the heme being used by A. hydrophila, while globin is the main source of energy in leech food [23]. In contrast, in human tissues $A$. hydrophila is known to be a highly pathogenic bacterium, reason why parenteral antibiotic prophylaxis with 3rd generation cephalosporins or cefotaxim is indicated [24].Oral antibiotics with proven efficacy in the prophylaxis of A. hydrophila infections are ciprofloxacin, tetracycline, and trimithoprim-sulfometaxazole [25].

In our study, 12-day prophylaxis with ciprofloxacin was administered after MLT initiation in all patients, no infectious complication with A. hydrophila isolation being identified at the serial microbiological examinations ofthesecretions collected from the wounds. Despite these good results obtained by us, practitioners should always keep in mind that MLT-related infections should be avoided by prophylactic antibiotic therapy, as the literature reports suggest that they affect $7 \%$ to $20 \%$ of the patients who undergo MLT and could decrease flap survival rate by up to $30 \%$ [26, 27].

Another extremely rare complication, but described in the literature, is prolonged or even lifethreatening bleeding from leech bite wound, although we did not encounter such complications in our study cases. Our patients were closely monitored clinically and hematologically to exclude the presence of excessive bleeding, thus blood transfusions bring avoided in all patients [28]. Yet, there is no protocol regarding the use of leeches to reduce venous congestion or a universally-accepted consensus on the number of simultaneously used leeches and the duration of their use. To reduce the incidence of complications, the number of leeches to be used per sessionshould be as small as possible, but at the same time large enough to ensure the survival of the tissue affected by venous congestion [29].

Generally, the daily number of leeches and the duration of MLT are based on surgeon's experience in identifying local signs of decreased venous congestion after MLT initiation, such as diminution of cyanosis, bleeding stopped after leech detachment, or improved capillary refill time [30]. The lack of universally accepted protocols is due to the variable number of needed leeches, depending on the size of the congested tissue and severity of venous insufficiency [31]. In line with the previously mentioned principles, we adjusted the number of applied leechesto the clinical signs at the level of replanted anatomical segments. In the current study placed 2 to 4 leecheswereappliedper day, and the duration of treatment ranged from 4 to 7 days that is until the development of neovascularization and disappearance of the signs of venous insufficiency.

It was found that the larger the amputated segment, the greater the number of leeches used daily, and the longer their application over time.Chepeha recommends a protocol of 3 leeches per hour and the Iowa head and neck protocol a leech every 2 hours [29, 30]. MLT should be administered until venous return is resumed, as we did in this study. In most cases, leeches are used for 2 to 6 days [21]. In fact, most often treatment duration is established empirically, based on subjective appreciation of skin color, capillaryrefill, color of the blood oozing from the leech bite [21]. There are cases in which leeches cannot be used: arterial insufficiency, hemophilia, hemorrhagic diathesis, blood cancers, anemia, sepsis, HIV, hepatobiliary disease, cachexia, intolerance to leeches, pregnancy, lactation, treatments with anticoagulants, immunosuppressants [21].The success rate of MLT in tissue decongestion is reported to be $70-80 \%[6,26]$. 


\section{Conclusions}

Biological leeches have in their saliva over 20 bioactive molecules with analgesic, antiinflammatory, platelet inhibitory, anticoagulant, thrombin regulatory, and antimicrobial functions. MLT cannot be defined as an alternative but rather complementary method. Its main advantages are: low-cost, relative ease of use, and high effectiveness. Patient consent and collaboration, as well as psychological preparation before using MLT are essential. The usefulness and use of leeches are possible and indicated not only in plastic surgery but also in the treatpathologies.

\section{References}

1.SIG, A.K., GUNEY, M., USKUDAR, A., OZMEN, E.,Integr. Med. Res., 6, no. 4, 2017, p. 337. 2.ABDUALKADER, A.M., GHAWI. A.M., ALAAMA, M., AWANG, M., MERZOUK, A., Indian. J. Pharm. Sci., 75,no.2, 2013, p. 127.

3.JOSE, M., VARGHESE, J., BABU, A.,J.Maxillofac. Oral. Surg.,14, Suppl. 1, 2015,p. 251.

4.UPSHAW, J., O`LEARY, J.P., Am. Surg., 66, no.3, 2000, p. 313.

5.SRIVASTAVA, A., SHARMA, R., Arch. Appl. Sci. Res., 2,2010,p. 271.

6.WHITAKER, I.S., RAO, J., IZADI, D., BUTLER, P.E., Br. J. Oral.Maxillofac. Surg., 42, no.2, 2004, p.133.

7.HAYCRAFT, J.B., Proc. Roy. Soc. Lond., 36, no. 1, 1883, p. 478.

8.MARKWARDT, F., Methods in Enzymology, New York, Academic Press, 19, 1970, p. 924.

9.DEGANC, M., ZDRAVIC, F., British Journal of Plastic Surgery, 13, 1960, p.187.

10.FOUCHER, G., HENDERSON, H.R., MANEAU, M., MERLE, M., BRAUN, P.M., Int. J.Microsurg. 3, 1981, p.265.

11.FRODEL Jr., J.L., BARTH, P., WAGNER, J., Otolaryngol. Head Neck Surg.,131, no.6, 2004, p. 934.

12.VERRIERE, B., SABATIER, B., CARBONNELlE, E., MAINARDI, J.L., PROGNON, P., WHITAKER, I., LANTIERI, L., HIVELIN, M., Eur. J.Clin.Microbiol. Infect. Dis., 35, no.6, 2016, p. 1001.

13.WHITLOCK, M.R., O’HARE, P.M., SANDERS, R., MORROW, N.C., Br. J.Plast. Surg., 36, no. 2, 1983, p. 240.

14. MENDENHALL, S.D., SAWYER, J.D., ADKINSON, J.M.,Eplasty,16, 2016, p. e39.

15.MOMENI, A., LIU, X., JANUSZYK, M., WAN, D.C., BUNCKE, G. M., BUNTIC, R.F., PARRETT, BM., Microsurgery, 36, 2016, no.4, p. 345.

16.WHITAKER, I.S., CHEUNG, C.K., CHAHAL, C.A., KAROO, R.O., GULATI, A., FOO, I.T.,Br.

J. Oral Maxillofac. Surg., 43, no. 2,2005, p. 155.

17.MARKWARDT, F., Biomed. Biochim. Acta,44, 1985, p. 1007.

18.BROWN, J.E., BAUGH, R.F., HOUGIE, C.,Thromb. Res., 17, no. 1-2,1980, p. 267.

19.BASKOVA, I.P.,ZAVALOVA, L.L., Biochemistry (Moscow), 66, no. 7, 2001, p.703.

20.BARNES,C.S.,KRAFFT, B., FRECH, M., HOFMANN, U.R., PAPENDIECK, A., DAHLEMS, U., GELLISSEN, G., HOYLAERTS, M.F.,Semin.Thromb.Hemost., 27, no. 4,2001, p. 337.

21.CHENG, R.M., TANG, X.P., LONG, A.L., MWANGI, J., LAI, R., SUN, R.P., LONG, C.B., ZHANG, Z.Q., Zool. Res., 40, no. 3, 2019, p. 205.

21.CHENG, B., LIU, F., GUO, Q., LU, Y., SHI, H., DING, A., XU, C., PeerJ, 7, 2019, p. e7716.

22.RICHERSON, J.T., DAVIS, J.A., MEYSTRIK, R., Lab. Anim., 24, no. 2, 1990, p. 147.

23.HERMANSDORFER, J., LINEAWEAVER, W., FOLLANSBEE, S., VALAURI, F.A., BUNCKE, H.J., Br. J. Plast. Surg., 41, no. 6, 1988, p. 649.

24.BRAGA, A., LINEWEAVER, W.C., WHITNEY, T.M., FOLlANSBEE, S., BUNCKE, H.J., J. Reconstr. Microsurg.,6, no. 2, 1990, p. 135.

25.CHALAIN, T.M., J. Reconstr. Microsurg.12, no. 3, 1996, p. 165.

26.OLIVER, J.D., DELOUGHERY, E.P., GUPTA, N., BOCZAR, D., SISTI, A., HUAYLLANI, M.T., RESTREPO, D.J., HU, M.S., FORTE, A.J., Medicina (Kaunas), 55, no. 5, 2019, p. 208. 
27.SAHA, P.K., ROY, S., BHATTACHARYA, D., MUKHERJEE, P., NASKAR, T., BHUIYA, A., Med. Gen. Med., 7, no. 4, 2005, p. 73.

28.ROTHENBERGER, J., PETERSEN, W., SCHALLER, H.E., HELD, M., Wound Repair Regen.,24, no. 6, 2016, p. 1023.

29.KASHIWAGI, K., HASHIMOTO, I., ABE, Y., KOTSU, K., YAMANO, M., NAKANISHI, H., J. Med. Invest., 60, no. 3-4, 2013, p. 213.

30.ELYASSI, A.R., TERRES, J., ROWSHAN, H.H., Oral Surg. Oral Med. Oral Pathol. Oral Radiol.,116, no. 3, 2013, p. e167.

Manuscript received: 30.12 .2019 